\title{
ESTUDOS PRELIMINARES SOBRE AS CARACTERISTICAS MORFOLÓGICAS DO POLEM DE ABACAXIZEIROS [Ananas comosus (L.) MERRIL] ${ }^{\star}$
}

\author{
LUIZ ANTONIO ROCHELLE** \\ ELOYS JACSKMOLLEY GIACOMELLI***
}

\section{RESUMO}

Hodiernamente, o estudo sobre o grão de polem tem alcançado importância muito grande. O tamanho e o contorno, o número e a posição dos sulcos, o número e a posição das aberturas, assım como, os detalhes na ornamentação da parede, principalmente da exına, constituem os principais caracteres morfológicos dos grãos de polem, que oferecem subsídios mormente à Taxonomia Vegetal.

O material utilizado no presente trabalho, foi obtido da coleçâo de abacaxizeiros, pertencentes à Estação Experimental de Limeira-Cordeirópolis (SP).

Objetivamos estudar comparativamente, a morfologia dos grãos de polem, provenientes de espécies diferentes.

Utilizamo-nos de dois processos para obtenção de lâminas, para posteriores exames ao microscópio: método rápido e método da acetólise.

Constatamos que, a maioria do material examinado ao microscópio, apresentou grãos de polem isolados, monoporados, com a exina reticulada, com sulcos longitudinais, de formas predominantemente esféricas ou ovóides.

Muito embora trabalhássemos com material de espécies distintas, não houve diferenças morfológicas evidentes, nos grãos de polem examinados, "tanto para o método não acetolítico (rápido) como para o método da acetólise.

\section{INTRODUÇÃO}

É grande a contribuição dos estudos sobre as características morfológicas dos grãos de polem à Taxonomia e outras ciências como a História da Vegetação e do Clima, Arqueologia, Medicina, Geologia e Ecologia.

Segundo ERDTMAN (1943), citado por OLIVEIRA SANTOS (1ऽ61), referindo-se ao campo das aplicações, aponta os trabalhos de VON POST (1916) e POTONIE (1934), os quais estudaram polem fóssil; ZANDER (1935), que tratou de polem nos méis e WODEHOUSE (1935) que se ocupou do polem da atmosfera.

\footnotetext{
* Entregue para publicação em 5/12/1975.

* Departamerito de Botânica - ESALQ/USP.

** Seção de Frutas Tropicais, Instituto Agronômico de Campinas.
} 
Os estudos sobre as características morfológicas dos pólens, confirmam realmente seu valor taxonômico, como excelentes subsídios à distinção de grupos, famílias, gêneros e até espécies botânicas.

Considerando pois, a associação das características da forma, tipo e número de sulcos, tipo e número de poros, ornamentação da exina e sua estrutura, pode o estudioso identificar as plantas. - O resumo deste trabalho foi apresentado na XXIV Reunião Anual da Sociedade Brasileira para o Progresso da Ciência, em julho de 1972, na cidade de São Paulo.

\section{MATERIAL E MÉTODOS}

Material - Utilizamo-nos dos seguintes abacaxizeiros, constantes da coleção da Estação Experimental de Limeira (Cordeirópolis, SP).

- Ananas comosus (L.) Merril, cv. Amarelo (Tatui), 'Boituva', 'Amarelo-comum'.

- Ananas comosus (L.) Merril, cv. Branco, 'Pernambuco', 'Pérola'.

- Ananas comosus (L.) Merril, cv. Smoth-cayenne, 'Cayenne'.

- Ananas ananassoides (Baker) L.B. Smith var. typicus (I-43850), Ananás-do-campo.

- Ananas bracteatus (Lindl.) Schultes, var. rudis L.B. Smith (I-43852), Ananás-vermelho-do-mato.

- Ananas comosus (L.) Merril, cv. Cochinchinensis (I-43871).

- Ananas bracteatus (Lindl.) Schultes, var. albus (I-43851), Selvagem-branco, Ananás-branco-do-mato.

- Ananas lucidus Miller, Ananas erectifolius L.B. Smith (I-43925), Curauá-da-amazônia.

Os botões florais foram colhidos antes da abertura floral, posteriormente levados ao laboratório e conservadios em água pura, favorecendo desta maneira, a antese normal das flores, evitando também a provável contaminação com polem de outras piantas. Em seguida, retiramos as anteras das fiores já abertas, colocamo-as em um tubo de ensaio, contendo em partes iguais, éter, acetona, mais água destilada. O material assim, foi levado para as peneiras de fio de aço inoxidável, com 50 micros de diâmetro e malhas com aberturas de 175 micros. O polem retirado fícou em suspensão no líquido, ao passo que a matéria graxa e oleosa se dissolveu no éter e acetona. $O$ filtrado sem as anteras e suas partes, foi centrifugada a 3.000/4.000 rpm durante 5 minutos. Mais tarde, por decantação, todo o líquido foi eliminado, permanecendo no fundo somente o material polínico.

Métodos - O material polínico assim obtido foi tratado por dois processos:

- Método rápido-polem. não ace tolizado, montado em geléia de glicerina, com ou sem a adição de algumas gotas de Fucsina básica, colocada quando a geléia ainda estava quente. Em seguida preparamos as lâminas. 
- Método da acetólise - neste método tratamos o material polínico, segundo OLIVEIRA SANTOS (1961).

a) O material polínico obtido foi tratado com hidróxido de potássio a $10 \%$, em seguida foi levado ao banho-maria, durante o tempo de 1 minuto; depois centrifugado, decantado e lavado em água destilada e novamente centrifugado.

b) Acrescentamo-lhe 2,5 cc de ácido acético glacial, novamente o material foi centrifugado e decantado.

c) Adicionamo-lhe 2,5 cc de anidrido acético, com 3 gotas de ácido sulfúrico concentrado; levamos ao banho-maria por 1 minuto, sempre agitando todo o material. $\mathrm{O}$ material ainda quente, foi outra vez centrifugado e decantado.

d) Em seguida, o material foi lavado em 2,5 cc de ácido acético; centrifugado, decantado e novamente lavado em água destilada.

e) O material lavado após a decantação foi tratado mais uma vez com hidróxido de potássio a $10 \%$ para alcalinizá-lo; outra vez centrifugado, decantado e lavado com água destilada. Em seguida as lâminas permanentes foram montadas.

\section{RESULTADOS E CONCLUSĀo}

Os grãos de polem examinados ao microscópio apresentaram as seguintes características morfológicas:

Grãos de polem monoporados (raríssimos biporados).

A sexina apresentou sempre reticulada.

Todos os grãos de polem são sulcados (às vezes 2 sulcos) longitudinalmente, são pois grãos de polem colpados, às vezes bicolpados.

Grãos de polem isolados, exceção a espécie Ananas bracteatus (Lindl.) Schultes var. albus (I-43851) - Selvagem-branco ou Ananás-branco-do-mato.

Houve predominância de grãos de polem de formas esféricas e ovóides.

Assim, constatamos que não houveram diferenças morfológicas evidentes, nos dois processos utilizados, ou sejam Método rápido e Método da Acetólise, muito embora as cultivares estudadas fossem oriundas de espécies diferentes. 


\section{SUMMARY}

\section{PRELIMINARY STUDIES ABOUT POLLEN MORPHOLOGICAL CHARAC- TERISTICS OF PINEAPLE [Ananas comosus (L.) MiERRIL]}

Nowadays, the study of the pollen grains has reached great importance. The size, the countour, the number and position of the grooves; the number and position of apertures as well as details of the wall decoration, mainly of the exine, constitute the principal morphological characteristics of the pollen grains. Such elements thus provide aids to Plant Taxonomy mainly.

The material used in the present work was obtained from the Limeira Experimental Station pineaple plant collection in Cordeirópolis, SP - Brasil.

Our aim was to study comparatively the morphology of the pollen grains picke: up from different species.

We made use of two processes for the obtention of slides for microscope examination afterwards - the speed method and acetolysis method. We noted that most of the material examined on the microscope showed isolated and monopored pollen grains with reticulate exine besides lenthwise grooves and with predominantly ovate or spherical shapes.

Although, we worked with material of different species there were no evident morphological differences among the examined pollen grains neither with the speed method (the non-acetolic method) nor with the acetolic method.

\section{LITERATURA CITADA}

COLLINS, J.L., 1969. Pineapple: Botany, Cultivation and Utilization. London, Leonard Hill. p. 28-37.

GIACOMELLI, E.J., 1972. Estudo sobre o comportamento do abacaxizeiro [Ananas comosus (L.) Merril], cultivar Cayenne na região de Bebedouro, Estado de São Paulo, Piracicaba, Tese, $37 \mathrm{p}$.

HEYWOOD, V.H., 1970. Taxonomia Vegetal. São Paulo, Companhia Editora Nacional, 107 p.

LABOURIAU, M.L.S., 1971. Contribuição à Palinologia dos Cerrados. Sẫo Paulo, Tese, 279 p.

MARQUES, M. \& MELHEM, T.S., 1966. Pollen Grains of PLants of "Cerrado". XI - Apocynaceae. An. Acad. Bras. Ciền., 38(2):371-378.

SANTOS, C.F.O., 1963. Características morfológicas dos grãos de polem das principais plantas apícolas. Anais da E.S.A. "Luiz de Queiroz", $20: 175-228$.

WODEHOUSE, R.P., 1929. Pollen grains in the identification and classification of plants. IV - The Mutisieae. American Journal Botany, XVI (5). 